\title{
Progress in Materials for Can Stock and Future Trends
}

\author{
Gilbert G. KAMM \\ Retired Director of Materials Technology, American National Can Company, Barrington, IL 60010, U.S.A.
}

\begin{abstract}
Developments in electrolytic tin plate, tin-free steel and more recent low tin materials are described with emphasis on their corrosion performance and their applicability to the newer can manufacturing processes. The significance of tinplate special property tests and their relative importance are discussed as related to corrosion performance in cans for moderate to high corrosivity food products. Information regarding pitting corrosion of aluminum killed continuous cast tinplate in cans for light colored fruits is also reviewed. Tin-free and low tin materials are being used in drawn and welded cans, but better enamel coverage is required than for tinplate cans. Long term trends show that aluminum has taken over most of the beer and soft drink market but its use in food cans remains very limited. New processable multilayer plastic barrier materials have been introduced as cans, bowls and trays for single serving microwaveable foods, which could have a significant impact on metal cans. The solid waste issue and recyclability of the various materials is discussed. A new process for improving the quality of sheif stable processed foods is also described.
\end{abstract}

KEY WORDS: tin plate; tin-free steel; corrosion resistance; can for foods; can for drinks; enamel coverage; multilayer plastic barrier materials; recyclability; aluminium plate.

\section{Introduction}

It is a great pleasure to be here with you today. Your invitation to me to give the 1989 Yukawa Memorial Lecture is a high honor, indeed. Having read the history of Mr. Yukawa's career and his many accomplishments, I am certain that his efforts have had a great influence on the steel industry in Japan and the constant search for new technology which has made your country a world leader in the production of steel and steel base materials.

When Mr. Yukawa joined the Yawata Steel Works in $1926 \mathrm{I}$ was just one year old. My first exposure to the steel industry was 29 years later in 1955 when I started research on the corrosion resistance of electrolytic tinplate, and my first visit to Japan was in 1967 with Yawata Iron \& Steel Co., Ltd. At that time Yawata owned a controlling interest in Daiwa Can Co., Ltd. and was a licensee of American Can Co. for canmaking technology. My Company was a customer for tinplate, mainly for use in Hawaii. After the merger of Yawata and Fuji Iron and Steel Co., Ltd. in 1970 to form Nippon Steel Corporation, the canmaking technology agreement was directly with Daiwa, but periodic technical meetings with Nippon were continued. Over the years I have been consistently impressed by the amount of research and development effort and the continual upgrading of processes and facilities to take advantage of new technology, all of which has contributed to production of exceptionally high quality tin mill products. I am sure that if Mr. Yukawa were here today, he would be pleased with what has been accomplished from the technology base he helped to establish.

In my lecture today I will review the progress made in various tin mill products and the changes required to meet the needs of new can manufacturing methods. I will also discuss the impact of competing materials.

\section{Improvements in the Steel Base for Tinplate}

Before discussing developments in electrolytic tinplate, it is appropriate to review improvements made in tinplate steels before the introduction of electrolytic tinning. The first organized investigation into factors responsible for wide variations in corrosion resistance of tinplate was initiated in 1915. However, no real progress was made until 1923 when investigations which continued into the 1930 s were directed to the effect of base steel composition on performance of tinplate with a number of food products. The results of those studies have been thoroughly reviewed in the literature (Refs. 1)-5)) and will not be discussed in detail here. The findings led to specifications for tinplate steel chemistry, and classification of foods according to their corrosivity.

The specifications developed for steel chemistry are listed in Table 1. Type $\mathrm{L}$ is the most restrictive for use in cans for highly corrosive products, with maximum amounts set for all of the elements listed. The Type MR specification for moderately corrosive products is less restrictive, allowing slightly higher phosphorus and copper than for Type L, and having no limit indicated for the residual elements, nickel, chromium, molybdenum and arsenic. Type MG allows higher phosphorus to provide higher strength but can be used only with canned products having low corrosivity. For Type $\mathrm{L}$ or MR aluminum killed continuous cast steels, aluminum is allowed up to $0.10 \%$, and up to $0.03 \%$ of silicon extracted from refractories has shown no adverse effects on corrosion perform- 
Table 1. Steel specifications for tin mill products.

\begin{tabular}{|c|c|c|c|c|}
\hline \multirow{2}{*}{ Element } & \multicolumn{4}{|c|}{ Ghemical composition (\%) } \\
\hline & Typ & $\mathrm{L}$ & Type MR & Type MG \\
\hline Carbon & 0.12 & nax. & $0.12 \max$. & $0.12 \max$. \\
\hline Manganese & 0.25 & 0.60 & $0.25-0.60$ & $0.25-0.60$ \\
\hline Phosphorus & 0.015 & $\max$. & 0.02 max. & $0.04-0.15$ \\
\hline Sulphur & 0.05 & $"$ & $\overline{0.05 \%}$ & 0.05 max. \\
\hline Silicon & 0.01 & $"$ & $0.01 \%$ & $0.01 "$ \\
\hline Copper & 0.06 & ” & $0.20 \%$ & $0.20 \%$ \\
\hline Nickel & 0.04 & $"$ & - & - \\
\hline Chromium & 0.06 & $"$ & $\ldots$ & - \\
\hline Molybdenum & 0.05 & ” & - & - \\
\hline Arsenic & 0.02 & ” & - & - \\
\hline
\end{tabular}

Table 2. Corrosion classifications for food products.

\begin{tabular}{lll}
$\begin{array}{c}\text { Class I } \\
\text { (Very corrosive) }\end{array}$ & $\begin{array}{c}\text { Class II } \\
\text { (Moderately corrosive) }\end{array}$ & $\begin{array}{c}\text { Class III } \\
\text { (Mildly corrosive) }\end{array}$ \\
\hline Cherries & Apples & Peas \\
Berries & Peaches & Corn \\
Apple juice & Pears & Meats \\
Prunes & Pineapple & Fish \\
Apricots & Citrus products & \\
Pickles & & \\
Sauerkraut & & \\
\hline
\end{tabular}

ance.

The corrosion classifications for food products are shown in Table 2. Class I includes very corrosive products which require $T_{y}$ pe $L$ steel. Class II products are normally only moderately corrosive and require only Type MR steel. The mildly corrosive Class III products require only Type MG steel.

\section{Electrolytic Tinplate}

The very first electrolytic tinplate was produced in the as plated, or matte, condition. Corrosion performance was very poor with products previously packed satisfactorily in cans produced from hot dipped tinplate. It was soon found that flow brightening the tin (melting and quenching) to provide a brighter and more attractive surface, also improved the corrosion resistance. There were still, however, great variations in performance from lot to lot in cans packed with Class I or Class II products.

The hydrogen evolution test described by Vaurio et $a l .^{6)}$ was the first laboratory test which correlated well with performance in packed cans. It was used successfully during the investigation which identified high silicon in hot pack rolled steels as the cause of catastrophic failures in peach cans in the 1929 and 1930 commercial packs. However, later problems in finding a gasket material for the test cell which did not adversely affect test results led to its abandonment.

The rate of pickling (pickle lag) test and the iron solution (ISV) test developed by Willey et al. ${ }^{7)}$ were the first tinplate special property tests to become specifications for heavily coated electrolytic tinplate (No. 50 or heavier tin coating) intended for use in cans for

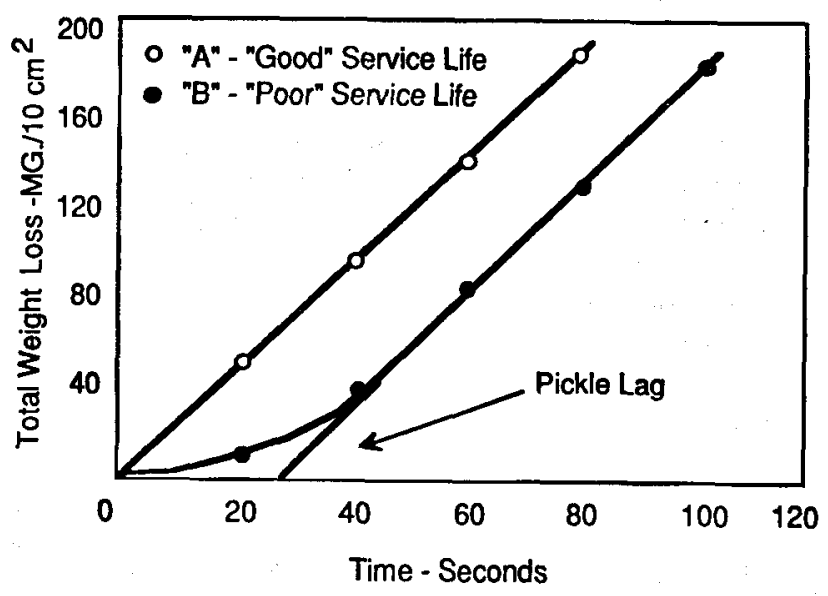

Fig. 1. Rate of pickling test comparing good steel A and poor steel B.

Table 3. Annealing atmospheres.

\begin{tabular}{lll}
\hline & \multicolumn{1}{c}{$\mathrm{DX}$} & $\mathrm{HNX}$ \\
\hline Hydrogen & $10-12 \%$ & $5-7 \%$ \\
Carbon monoxide & $8-9 \%$ & trace \\
Carbon dioxide & $5-6 \%$ & trace \\
Methane & $1-1.5 \%$ & trace \\
Nitrogen & balance & balance \\
Dewpoint & $+5^{\circ} \mathrm{C}$ & $-40^{\circ} \mathrm{C}$ \\
\hline
\end{tabular}

corrosive food products.

The rate of pickling test measures the rate of corrosion of the steel in hot $1 \mathrm{~N}$ hydrochloric acid either before tinning or after detinning to the steel base. A slow initial rate (pickle lag) as opposed to a constant rate right from the start, as shown in Fig. 1, indicates the presence of a surface condition which is not fully understood but which can cause early failures in prunes and some other products. Koehler ${ }^{8)}$ has attributed the pickle lag to selective oxidation of grain boundaries during annealing, and Koehler and Canonico ${ }^{9)}$ have shown that this can cause the steel surface to be anodic to tin in prunes and peaches. The cause of pickle lag was traced to the use of low cost DX anncaling atmosphere described in Table 3 . It has a high moisture content which, in combination with hydrogen, can cause the oxidation responsible for the pickle lag; it also contains carbon monoxide and methane which can be detrimental to the steel surface. The change to HNX atmosphere, which contains mainly hydrogen and nitrogen and has a low dew point, precludes the possibility of developing high pickle lag. The rate of pickling test serves as a valuable control tool for monitoring the annealing process.

The iron solution test is considered the most important of the special property tests. It measures the amount of iron dissolved when a standard area of tinplate is exposed to a solution containing sulfuric acid, hydrogen peroxide and ammonium thiocyanate for $2 \mathrm{hr}$ at $80^{\circ} \mathrm{F}$. Any plate giving an ISV (iron solution value) appreciably greater than $20 \mu \mathrm{g}$ of iron is likely to give substandard performance in unenameled cans packed with Class I or Class II products. Plates with 
very high ISV ( 40-100) have caused catastrophic failures in grapefruit juice after only 3 to 6 months at normal storage temperatures. The ISV test is essentially a measure of the amount and activity of the steel surface exposed through the tin and alloy layers to an acid solution in which the steel is anodic to tin. There is appreciable detinning and some exposure of the iron-tin alloy during the test; thus the result is affected by porosities of both the tin and alloy layers. Since the test medium does not simulate any food product, it serves as a general, but very valuable, test for monitoring quality of heavily coated electrolytic tinplate.

Tin crystal size (TCS) was adopted as a specification because experience had shown that in many cases of poor corrosion performance the size of the crystals in the tin coating tended to be small. The consensus has been that the small crystal size does not cause the tin to corrode appreciably faster but, rather, the condition causing the plate to perform poorly also tends to prevent the formation of large tin crystals during the melting and quenching on the electrotinning line. Presence of small tin crystals has been considered mainly a warning that ISV may be high or the steel surface may be less than ideal for best performance in the more corrosive foods. More recently, Bird ${ }^{10)}$ has reported significant effects of tin crystal size on tin corrosion rates in a test pack of grapefruit where other special properties were held constant.

The alloy-tin couple (ATG) test described by Kamm et al. ${ }^{11)}$ was the result of a search for the factors responsible for variations from average to superior performance in tinplates which met the pickle lag, ISV and TCS criteria. It was based upon studies ${ }^{12)}$ of the relationships between tin, iron-tin alloy and steel in air-free acid media and the effect of stannous ion in solution on those relationships. Grapefruit juice was chosen as the test medium representative of a number of products packed in plain (unenameled) tinplate cans because it gave better correlation with actual pack performance than did the synthetic media investigated. Carter and Butler ${ }^{13)}$ reported similar values for ATC tests conducted in tomato juice and pineapple juice, and considerably higher values in prune juice which is more corrosive. The electrochemical studies, combined with a new technique ${ }^{14)}$ for studying the alloy structure in the transmission electron microscope, led to a new theory of galvanic corrosion of tinplate controlled by the continuity of the tin and iron-tin alloy layers and the electrochemical behavior of the steel base exposed through those layers as detinning progresses. Proof of this theory was demonstrated ${ }^{15}$ ) with a Progressive ATG test in which couple currents were measured after increasing amounts of tin had been removed from the tinplate sample. This allowed calculation of detinning curves for plates with different ATCs and ISVs, which duplicated very closely the detinning measured for the same plates in an actual grapefruit juice test pack, as seen in Fig. 2. The solid lines represent data from test packs and the broken lines were calculated from Progressive ATG data. As you can see, the agree- ment is very close.

Electrolytic tinplate meeting pickle lag, ISV and TCS requirements listed in Table 4 has been classified as J Plate which should, with a No. 100 tin coating, give performance equivalent to that of common coke hot dipped tinplate. Tinplate meeting those requirements and also meeting the ATC specification, also shown in Table 4, is classified as $\mathrm{K}$ Plate which should give at least one third better performance in plain cans and certain enameled can applications, thus allowing a reduction in tin coating weight with no loss in performance as compared to $\mathrm{J}$ Plate with heavier tin coating.

All No. 50 or heavier electrolytic tinplate intended for use in cans for corrosion Class I or Class II products should be produced to at least J Plate specifications to avoid the risk of occasional financial losses from early failures in commercial packs. At present there are considerable quantitics of heavily coated plate produced as non-specification plate, for which the producer guarantees none of the special properties which define $J$ and $\mathrm{K}$ Plates. The risk of early failures in such cases depends upon the degrce of control exercised over tin mill processes. If the plate is being processed on the same lines as J or K Plate, good control of annealing and tin mill processes is more likely than if there are no checks made for pickle lag, ISV, tin crystal size or ATC on any of the plate produced.

The advantages for $\mathrm{K}$ Plate are illustrated in Fig. 3 which shows service life as time to first and $50 \%$ failures for one K Plate (coded X) and two J Plates (coded $\mathrm{Y}$ and $\mathrm{Z}$ ) in a number of products. All three have low pickle lag and ISV. The benefit is greatest

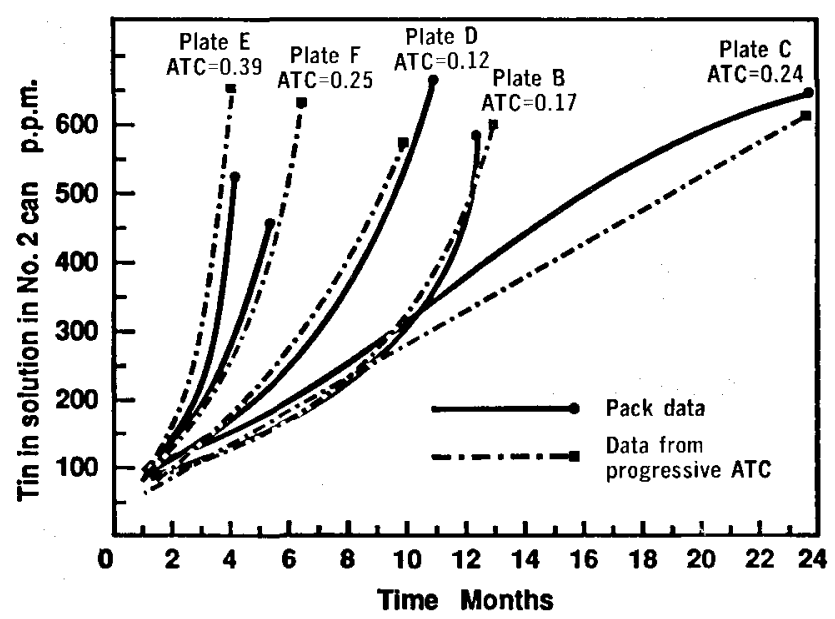

Fig. 2. Comparison of detinning calculated from progressive ATG with tin in the product in test pack.

Table 4. Special property requirements for $\mathrm{J}$ and $\mathrm{K}$ Plates.

\begin{tabular}{lll} 
& \multicolumn{1}{c}{ J Plate } & \multicolumn{1}{c}{ K Plate } \\
\hline Pickle lag & 10 sec max. & 10 sec max. \\
ISV & $20 \mu$ max. & $20 \mu g$ max. \\
Tin crystal size & ASTM \#9 or larger & ASTM \#9 or larger \\
ATG & - & Aim $0.05 \mu \mathrm{A} / \mathrm{cm}^{2}$ ave. \\
& & $0.12 \% "$ max. \\
\hline
\end{tabular}


Fig. 3.

Effect of ATC on performance with various products (all No. 100 tin coating-all low ISV and pickle lag).

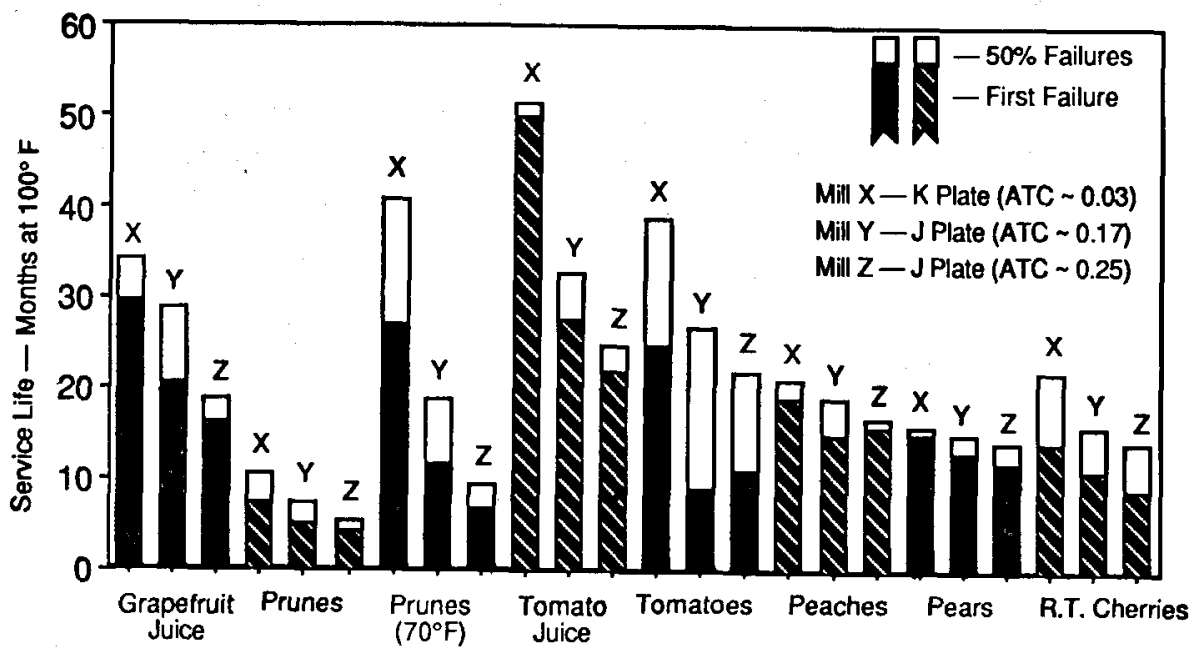

in plain cans for citrus products, tomatoes, tomato juice and prunes, and in enameled cans for Class I products such as cherries and various berries. The improvement from low ATC appears to be less in plain cans for peaches and pears which contain more malic acid and less citric acid, resulting in less galvanic action between the tin and the steel. This is related to the complexing strengths of the acids and the resultant effect on relative potentials of tin and steel as reported by Willey. ${ }^{16)}$

A number of possible methods for producing $\mathrm{K}$ Plate have been described in the literature (Refs. 17)-20)). Of the three approaches being used successfully today, by far the most widely practiced is the careful preparation of the steel prior to plating, combined with fairly heavy alloy weights of about 0.10 to $0.12 \mathrm{lb} . / \mathrm{BB}$ to obtain the required low ATC. The preparation may include cleaning before annealing, good annealing practice, and cleaning and pickling before tinning. One of the other two methods involves double plating-double melting ${ }^{21,22)}$ which produces low ATC at relatively low alloy weights around 0.07 to $0.08 \mathrm{lb}$./BB. The third method ${ }^{19)}$ employs a final tin plating-pickling in an acid bath containing a low concentration of stannous tin, just before entering the standard acid tinning bath; iron-tin alloy weights ranging from about 0.07 to $0.13 \mathrm{lb}$. $/ \mathrm{BB}$ are required for low $\mathrm{ATC}$, depending upon whether the steel is continuous or box annealed.

Kamm and his associates have expressed some concern $^{11,15,18)}$ that tinplate produced with heavy irontin alloy to achieve low ATG would not perform as well as expected because the higher temperatures needed to produce heavy alloy could cause coalescence of the tin coating. Coalescence could result in high ISV and/or accelerated detinning after early complete detinning of the thin areas of the coalesced tin coating. Heavy alloy also suffers greater damage than thinner alloy in can manufacture and beading of can bodies. Carter ${ }^{23)}$ demonstrated that tinplate produced on a pilot line with increasing alloy weight to lower the ATC did not always produce the expected improvement in corrosion performance, especially with plates exhibiting high ISV where increasing the alloy resulted in even higher ISV. Data presented from other plates produced on commercial tinning lines showed varying response to increasing alloy weight as determined by pack performance; unfortunately, no data were indicated regarding actual free tin and alloy weights, or values for ATC, ISV, pickle lag and tin crystal size to compare with the pack performance. Commercial experience indicates that alloy weights up to around $0.12 \mathrm{lb} . / \mathrm{BB}$ give satisfactory performance, provided all special property requirements are met.

\section{Abnormal Pitting Corrosion in Plain Cans for Light Colored Fruits}

With the introduction of continuous cast steels in the $1960 \mathrm{~s}$ it has generally been found that tinplate produced from aluminum killed continuous cast (AKCC) steels exhibits corrosion performance at least equal to that of tinplate produced from non-killed ingot cast (NK-IC) steels, while plate produced from silicon killed continuous cast steels showed poorer performance in a number of food products. ${ }^{24-28,30)}$ At present nearly all continuous cast steel used for food can stock is aluminum killed.

Starting in 1982 a number of large losses in commercial packs were encountered with hydrogen swells or perforations in cans produced from AK-CC tinplate packed with light colored fruits, including pears, peaches, fruit cocktail, mirabelle plums and apricots, while NK-IG stecls in many of the same packs gave normal performance. Chin $^{29)}$ reported failures with some AK-CG steels with low arsenic $(<0.010 \%)$ and failures in both AK-CG and NK-IC steels high in arsenic $(0.03$ to $0.08 \%)$. Commercial experience and results from limited test packs with commercial tinplates reported by $\mathrm{Kamm}$ et al.$^{30,31)}$ indicated that not all AK-CC tinplates are sensitive to the abnormal pitting corrosion and not all packs produced pitting with the sensitive plates. Also, the AK-CC steels with higher arsenic $(0.012$ to $0.04 \%$ ) showed greater sensitivity to pitting than those with $<0.01 \%$. Since 1984 arsenic has been controlled to levels below $0.01 \%$, eliminating that as one cause of sensitivity to corrosive packs.

The above observations led to an international industry sponsored investigation reported $^{32)}$ at the 
Fourth International Tinplate Conference and in a more recent summary report. ${ }^{33)}$ Results from test packs in 1985 and 1987 indicate that the abnormal pitting corrosion occurs only with occasional lots of AK-CC DR8-BA steel and only when used in packs having high corrosivity toward sensitive steels. The pitting occurs regardless of whether the tinplates meet $\mathrm{J}$ or K Plate specifications for pickle lag, ISV, TCS and ATG. The sensitive steels do not pit in packs with normal corrosivity and steels with low sensitivity do not pit in high corrosivity packs.

All NK-IG steels and the ten AK-CG continuous annealed (GA) steels tested showed no pitting in even the most corrosive packs, and the low sensitivity $\mathrm{AK}$ CG DR8-BA steels showed no pitting of consequence. More limited data suggest that a slightly higher temperature than normally used in box annealing, or perhaps just staying above some minimum temperature, would prevent the development of sensitivity in $\mathrm{AK}$ CC DR8-BA steels.

Oyagi and his associates ${ }^{34,35)}$ have studied enrichment of the steel surface during box annealing and suggest that optimization of steel chemistry and annealing conditions, including cleaning before annealing, may lead to practices which preclude the development of sensitivity in box annealed steels. Aubrun $e t$ $a l .{ }^{36)}$ have reported that stretching of the steel as in can manufacture produces microcracks a few micrometers deep in the surface of steels. They have established a procedure for determining the number of microcracks, or microcrack density (MD), after stretching the steel sample $1.5 \%$, which correlates well with sensitivity to pitting in light colored fruits. This test should be useful as a research tool for investigating the cffects of changes in box annealing practices.

The pitting corrosion was more serious with packs stored at 70 to $75^{\circ} \mathrm{F}$ than with those stored at $100^{\circ} \mathrm{F}$, indicating that use of higher storage temperature to accelerate results is likely to give misleading information. At $100^{\circ} \mathrm{F}$ storage there was less pitting and more detinning. Pennera et al. ${ }^{37}$ ) have proposed that the greater pitting at the lower temperatures is caused by adsorption of $\mathrm{CO}_{2}$ (from breakdown of organic acids) on the tin surface as a cathode, a reaction favored by lower temperatures. These same investigators found that degradation products of fructose contribute to corrosion of tin by direct attack, a process favored by higher temperatures.

Investigation of product and canning process variables indicated that use of good canning practices to minimize the amount of oxygen in the headspace and dissolved in the product is probably the most important factor in minimizing corrosivity toward sensitive steels. Preheating the syrup, good vacuum syruping and effective steam flow closure appear necessary. Other factors such as citric/malic acid ratio and type of sugar used for the syrup are undoubtedly involved, but extensive product analyses did not show clear-cut correlations with corrosivity. Kim and Helwig ${ }^{38}$ ) suggest that small amounts of sulphur or sulphur compounds can cause pitting, and the sulphur is sometimes very difficult to detect. It may be that the combination of high residual oxygen resulting from less than ideal canning practices, combined with high malic/citric acid ratio or other compositional factor, triggers the pitting phenomenon by reversing the tin and steel potentials during processing of the canned product, as observed by Tsurumaru et $a .^{39)}$ with cherries in syrup. Once initiated, the pitting could be self propagating.

Use of continuous annealed steel should eliminate the pitting problems with corrosive packs, but care should be exercised by the food packers to minimize product corrosivity through use of known good canning practices. Some adjustments in production of AK-CG DR8-CA steel or changes in flanging techniques by can manufacturers may be required to avoid flange cracks in can bodies. Changes in box annealing practices are likely which will provide a DR8-BA product with no sensitivity to pitting in corrosive packs and would not pose problems in can flanging.

\section{Tin-free Steel}

During my experience there have been many different types of tin-free steel materials. The first such materials were untreated temper rolled steel, commonly called black plate or CMQ (canmakers quality black plate). Later, double reduced steel had to be alkaline cleaned, lightly treated and electrostatically oiled with DOS (dioctyl sebecate). The treatment employed was usually a nitric acid rinse or a cathodic treatment in sodium dichromate. Resistance to rusting was poor and, although initial adhesion of organic coatings was relatively good, filiform corrosion under organic coatings, inks and varnishes was common, and undercutting corrosion and enamel lifting was also a problem. Soldering of can bodies was possible only with strong fluxes which accelerated corrosion.

During the 1950's, other chemically or electrochemically treated steels, mainly chromate or chromate-phosphate, became available which had somewhat better corrosion performance. However, they were even more difficult to solder than black plate or CMQ, and thus found use only as ends and in cemented lock seam bodies of cans for motor oil, detergents and other low corrosivity applications which did not involve pressure or vacuum in the can.

With the development of the high strength cemented lap sideseam can described by Kidder et al., ${ }^{40)}$ it soon became apparent that the chemically treated steels available at the time would not be adequate in the long term, especially for carbonated soft drink cans. Any metal exposure from incomplete coverage by the sideseam stripe allowed undercutting corrosion which resulted in iron pickup in the product and, in extreme cases, sideseam failure. Undercutting corrosion at any enamel damage on bodies or ends was also a problem. This led to evaluation of chromium plated steels then available in limited quantities from $J \operatorname{apan}^{\left.41^{-43}\right)}$ and the development of specifications for TFS-CT (chromium type), ${ }^{44)}$ also called ECCS (electrolytic chromium coated steel). The TFS-CT has 
been an excellent material. It has a lustrous surface resistant to discoloration during enamel baking, good resistance to rusting, plus exceptional enamel adhesion and resistance to undercutting corrosion of enameled plate exposed to corrosive products. The chromium oxide layer also prevents sulfide staining in certain food products. Yonezaki ${ }^{45}$ has reviewed various processes for producing tin-free steel, and also discusses metals other than chromium which have been considered.

Electrochemically, the chromium-chromium oxide surface has been found to be relatively inert and is cathodic to the base steel in acid media.44,46) However, the area of chromium or chromium oxide exposed is very small because of the very thin deposit and resistance to enamel undercutting, and it polarizes very readily cathodically, causing no apparent acceleration of steel corrosion at any enamel fractures or discontinuities. Because of these attributes, TFSCT was used successfully for a number of years in bodies and ends for beer and soft drink cans until the two-piece D \& I cans made from tinplate or aluminum were introduced which set new standards for allowable metal pickup in the product. The lap cemented sideseam is still used in the United States in TFS cans for hot filled cheese and in aluminum cans for processed luncheon meat. In Japan, lap seam cemented TFS cans have been very successful for hot fill coffee and juice drinks through the use of a special chromium-chromium oxide treatment having very low sulphate and fluoride content in the oxide ${ }^{47,48)}$ to provide the integrity required for these difficult applications.

One deficiency of TFS-CT is its poor weldability. Welded bodies have been made for a number of years by the process described by Chiappe, ${ }^{49)}$ but it is necessary to mechanically remove the chromium-chromium oxide from the steel surface at the sideseam margins in order to make the weld. The same is true for the newer wire welding processes where the high contact resistance of the TFS-CT surface allows too little latitude in welder settings to be practical for commercial production.

\section{Low Cost Materials for Welded Cans}

With the move from soldering to wire welding processes for three-piece can bodies there has been considerable effort devoted to development of low cost steel base materials with better weldability than TFSGT. Starting in 1978 a number of new materials were introduced which were lower in cost than No. 20 tinplate and were more easily welded than TFS-CT. These included LTS (lightly tin-coated steel) with No. 5 to No. 10 tin coatings with either CDC (cathodic dichromate) treatment or a light CT (chromiumchromium oxide) treatment similar to that used for TFS-CT. ${ }^{50-53)}$ In some cases the tin is left in the matte (unmelted) condition while others are meltcd to convert much, if not all, of the free tin to iron-tin alloy before the surface treatment. An extensive evaluation of a number of these materials, including nickel plated steel, was reported by Black and Helwig. ${ }^{54)}$ The best performers were the LTS materials, either matte or melted, and the chromium-chromium oxide CT surface treatment provided somewhat better enamel adhesion than a CDC treatment. The matte LTS showed the best weldability and nickel plate was most difficult to weld.

This parallels my own experience indicating that these new materials can be welded commercially, although there is less process latitude than with No. 20 tinplate. The nickel was found to be cathodic to steel in most corrosive media and accelerates corrosion of the steel base at any exposed areas. However, at least one can manufacturer in Japan has for some time been using a nickel plated steel successfully in welded cans for low corrosivity products.

Several modifications of LTS have been described which are intended to retain approximately $0.01 \mathrm{lb} . /$ $\mathrm{BB}$ of free tin after enamel baking to provide a lower melting surface with lower surface resistance and better weldability. Takano et $a{ }^{55)}$ describe a tin preplate converted to FeSn at high temperature and then plated with enough tin to leave a trace of free tin after enamel baking for good weldability. Moriyama et al. ${ }^{56)}$ employed a nickel preplate to prevent all of the free tin from being converted to alloy, and Mochizuki et al. ${ }^{57)}$ applied the nickel preplate before the continuous anneal to provide a nickel diffusion layer on the steel surface which results in an $\mathrm{Fe}-\mathrm{Ni}-\mathrm{Sn}$ alloy after the tin plating and melting. Some of these processes cause dewetting by the tin during melting, leaving the free tin in tiny droplets described as "dewey spread" by Miyazaki et al. ${ }^{58)}$ With light chromiumchromium oxide surface treatment, welding latitude was found to be almost equal to that of No. 25 tinplate and weld quality was better.

The corrosion performance of the LTS materials is similar to that of TFS-GT. At No. 5 tin coating essentially all of the free tin is converted to iron-tin alloy by the bakes required for enameling; the alloy is relatively inert and does not accelerate corrosion of the steel. However, the alloy does not act as a sacrificial anode and there is little or no free tin to provide stannous ions to inhibit steel corrosion. Thercfore, extremely good enamel coverage is required for products having moderate to high corrosivity.

The LTS materials also require lacquering or decorating on the outside to prevent rusting and to allow running through can and end making operations without scratching or abrasion. In Japan where most cans have a lithographed body, LTS materials are widely used because there is no additional lacquering required. However, in the United States where most food cans are not lithographed, an extra lacquering pass is required to protect the outside of the LTS body. Consequently, No. 5/20 tinplate is used with the No. 20 plain outside for food cans, or No. $20 / 5$ for coffee or nut cans which have lithography outside and are No. 20 plain inside, because the cost of an extra enameling or decorating pass would more than offset the savings from having the low tin both inside and outside. 


\section{Material Requirements for New Canmaking Process}

The new processes for manufacturing lead-free cans have placed new demands on the materials used. Fortunately, changes in steel and tin mill practices have met those demands.

The wire welding process requires close control of gauge, temper, steel cleanliness and tin coating weights. Uniform gauge and temper are required to obtain consistent overlap in the sideseam. Those properties and tin coating weight all affect weld quality. Good steel cleanliness is required to avoid flange cracks and bead fractures in light gauge double reduced can bodies.

The two piece can processes are even more critical. D \& I cans require close gauge control and higher steel cleanliness to avoid tear-offs in the wall ironer and cracked flanges which adversely affect productivity and spoilage. DRDI (draw-redraw with ironing) ${ }^{59)}$ and DTR (draw-thin-redraw) ${ }^{60}$ processes require even greater steel cleanliness and gauge control, minimal crown and feather edge, plus good formability and low earing as outlined by Klein and Hitchler, ${ }^{61)}$ and Sodeik et al. ${ }^{62}$

Improvements in continuous casting technology have resulted in tremendous improvements in cleanliness, surface quality and uniformity. And the aluminum killed steel, properly processed, provides the formability required for these severe forming operations. Improvements in hot and cold rolling technology have provided the needed control of gauge, crown, flatness and earing.

The new canmaking processes produce cans with less tin or no tin at all and with excellent enamel coverage, a situation that is changing the corrosion patterns with the more corrosive food products. For many years, enameled TFS-CT ends have been used successfully on enameled soldered tinplate bodies for moderately corrosive products with no real problems from perforations in the ends. Apparently, there was enough tin exposed on the soldered body to prevent serious corrosion at enamel fractures or abraded areas on the TFS-CT ends. With the new two-piece and welded cans which have essentially no tin exposed, there are more instances of perforations in the TFSCT ends where embossing, end fabrication or doubleseaming has fractured the enamel coating. Consequently, better enamel coverage is necessary on TFS-CT ends to avoid early perforations with moderate to high corrosivity products.

\section{Potential for Improved Materials}

\subsection{K Plate Production}

Limited test packs with nickel preplate made in 1953, before the ATC test was available, showed significant improvements in pack performance with a number of products ${ }^{18)}$ as seen in Table 5, and preplating of nickel or tin-nickel has been shown to produce low ATC. ${ }^{18,63)}$ With recent investigations of nickel preplating for LTS, it may be worth evaluating
Table 5. 1953 nickel preplate test packs.

Time to $50 \%$ failures at $100^{\circ} \mathrm{F}$ for No. 50 tin coating

\begin{tabular}{|c|c|c|c|}
\hline \multirow[t]{2}{*}{ Product } & \multirow{2}{*}{$\begin{array}{l}\text { Control } \\
\text { Months }\end{array}$} & \multicolumn{2}{|c|}{$0.03 \mathrm{lb} . / \mathrm{BB}$ nickel preplate } \\
\hline & & Months & $\%$ of control \\
\hline Prunes & 3.5 & 4.0 & 114 \\
\hline Grapefruit & 8.4 & 11.1 & 132 \\
\hline Peaches & 13.2 & 18.2 & 138 \\
\hline Tomato juice & 13.8 & 22.3 & 162 \\
\hline Green beans & 5.7 & 9.3 & 163 \\
\hline
\end{tabular}

its effect on pack performance of heavily coated $\mathrm{K}$ Plate.

Better uniformity of the tin coating over the peaks and valleys of the base steel topography is another possibility for improving performance of $\mathrm{K}$ Plate. The anodic treatment prior to melting on the tinning line described by Ooniwa et al. ${ }^{64}$ ) shows an intriguing possibility.

In any investigations of new processes, the special property tests are valuable for assessing their effectiveness, but any promising materials should be thoroughly tested in packs with a number of products to confirm the improved performance predicted by the laboratory tests.

\subsection{Improved Surface Treatment for Tinplate}

The excellent lacquer adhesion to TFS-CT and recent experience with the chromium-chromium oxide CT treatment on LTS materials suggest that application of the CT treatment to tinplate might provide adhesion better than now obtained from the best CDC or SDCD treatments. This would be applicable mainly to the lighter No. 20 and 25 tin coatings for inside lacquered cans, or to precoated drawn cans where lacquered GDC treated tinplate has insufficient adhesion.

The CT treatment may not be applicable to No. 50 or heavier tin coatings for plain can applications where its greater passivity may prevent the tin from providing cathodic protection to the base steel or will result in unsightly spotty detinning in plain cans for products such as bamboo shoots, mushrooms or asparagus. Takasue et $a l .^{65}$ have reported early localized detinning in plain cans for bamboo shoots; tin in solution decreased somewhat with increasing chromium-chromium oxide levels and iron increased very slightly. Test packs of a full range of products packed in plain cans would be needed to determine the effect of the CT treatment on container performance.

\section{Trends in Materials and Containers}

During 1987, $70 \%$ of all cans produced in the United States ${ }^{66)}$ were made from aluminum. Table 6 provides a break-down of production comparing steel $v s$. aluminum and 2-piece $v s$. 3-piece. Virtually $100 \%$ of the 36.5 billion beer cans and $93 \%$ of the 40.3 billion soft drink cans were aluminum, while $93 \%$ of the 28.4 billion food cans were made from steel. Metal cans for general packaging (aerosol, 
Table 6. 1987 can production in the United States steel $v s$. aluminum and 2-piece $v s$. 3-piece.

\begin{tabular}{|c|c|c|c|c|}
\hline & \multicolumn{2}{|c|}{$\%$} & \multicolumn{2}{|c|}{$\%$} \\
\hline & Steel & Aluminum & 2-piece & 3-piece \\
\hline $\begin{array}{l}\text { All cans } \\
\text { (109. } 2 \text { billion) }\end{array}$ & 30 & 70 & 77 & 23 \\
\hline $\begin{array}{l}\text { Beer } \\
\quad(36.5 \text { billion })\end{array}$ & 0.1 & 99.9 & 100 & 0 \\
\hline $\begin{array}{l}\text { Soft drink } \\
\quad(40.3 \text { billion })\end{array}$ & 7 & 93 & 100 & 0 \\
\hline $\begin{array}{l}\text { All food } \\
(28.4 \text { billion })\end{array}$ & 93 & 7 & 27 & 73 \\
\hline Baby food & 100 & 0 & 30 & 70 \\
\hline Coffee & 100 & 0 & 0 & 100 \\
\hline Dairy products & 82 & 18 & 24 & 76 \\
\hline Fruit \& Juices & 92 & 8 & 11 & 89 \\
\hline Meat \& Poultry & 51 & 49 & 64 & 36 \\
\hline Pet food & 84 & 16 & 51 & 49 \\
\hline Sea food & 96 & 4 & 77 & 23 \\
\hline $\begin{array}{l}\text { Vegetables \& } \\
\text { Juices }\end{array}$ & $99.9+$ & $0.01-$ & 12 & 88 \\
\hline Other, incl. soup & 99 & 1 & 13 & 87 \\
\hline General & 99 & 1 & 3 & 97 \\
\hline
\end{tabular}

paint, automotive, etc.) were still $99 \%$ steel. For foods, aluminum has made the greatest inroads in cans for meat and poultry, pet foods and dairy products, and to a lesser extent for fruits and seafood.

Considering container type, $77 \%$ of all cans were 2-piece in 1987 because of the large volume of D \& I beer and soft drink cans. $27 \%$ of all food cans were 2-piece, many of which were drawn or DRD, but with an increasing number of steel D\&I cans. Most of the 3-piece food cans already are welded, except for some HTF pure tin soldered cans ${ }^{67)}$ for asparagus or tomato products, where there have been problems with spotty or rapid detinning of plain cans or underfilm detinning of enameled cans.

The trends in metal usage in the United States from 1982 through 1987 are shown in Fig. 4. The total number of cans for food and general has remained quite constant and the increase in aluminum is very small. Soft drink can production increased substantially, but the already small volume still in steel dropped from 5.6 billion cans in 1982 to 3.0 billion in 1987. Beer was been essentially $100 \%$ aluminum all during this period. During the first nine months of $1988,{ }^{68)}$ beer cans remained almost totally in aluminum with only a $1.2 \%$ increase in number of cans produced, while cans for soft drinks increased almost $12 \%$ with the steel share remaining about $7 \%$ of the total soft drink market, despite higher aluminum prices which increased the already substantial cost differential between the two materials.

There appear to be two factors involved in the preference for aluminum by the beer and soft drink industries. One is elimination of any possibility for iron pick-up to affect product flavor, even though steel D\&I cans can be produced which are perfectly adequate to safeguard product quality. The second factor is the scrap value of the aluminum cans for recycling and the successful efforts of environmentalists and aluminum producers to achieve a high level of

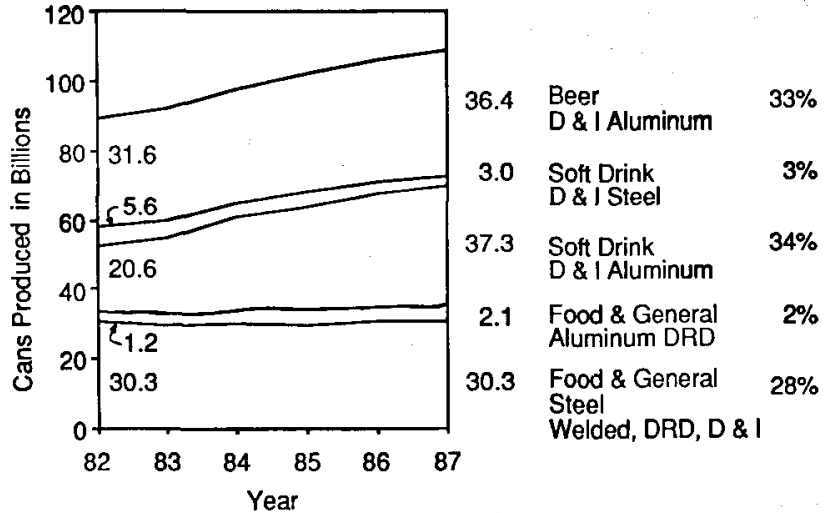

Fig. 4. Trends in the United States-Number of cans produced and percent of total.

recycling of aluminum cans. Steel cans are also recyclable but the number recycled has been relatively small. In 1988 the Steel Can Recycling Institute was formed by the American Iron and Steel Institute as a unified effort to promote the recyclability of used steel cans and create a market for them.

The drawn aluminum food can which received considerable publicity several years ago ${ }^{69,70}$ ) has not yet been commercialized. It has been demonstrated that a triple draw DRD container can be produced from unenameled standard can stock alloys. When electrocoated anodically with available electrocoat materials, it provides excellent corrosion performance with a wide range of food products except for those fruit products which require some tin from plain tinplate cans in order to retain good color. One of the biggest drawbacks is the high cost of the aluminum required for processed food cans. With the strongest alloys available which are suitable for the DRD or DRDI processes, there is a very large material cost disadvantage as compared to precoated TFS-CT DRDI or DTR cans, or No. 25 tinplate D\&I, much greater than the differential between aluminum and steel for D\&I beer and beverage cans. The value of the used aluminum can for recycling was cited as a compensating factor for the high raw material cost.

Trends in Japan as reported by $\mathrm{Hada}^{71)}$ show continuing growth in beverage cans totaling 23.9 billion in 1987, up from 20 billion in 1986, while food can production has remained level at 2.4 billion. Fig. 5 shows trends by type of can and material for 1980 through 1987. It was surprising to note that $35 \%$ of all cans produced are TFS cemented lap seam cans for coffee, Oolong tea and juices, where the 3-piece can is needed to withstand the vacuum developed with hot fill and processed products. With development of the new L'TS materials, presumably these could be converted to welded cans. The use of D\&I aluminum cans for Oolong tea, filled with liquid nitrogen flushing, was recently announced by one company. ${ }^{72}$ ) Welded cans have grown to $23 \%$ while soldered have decreased to $7 \%$. D\&I aluminum for beer and beverage accounts for $28 \%$ and is increasing, while D\&I steel has decreased to $6 \%$. Only about $1 \%$ are drawn cans. Overall, $72 \%$ of all cans were still 


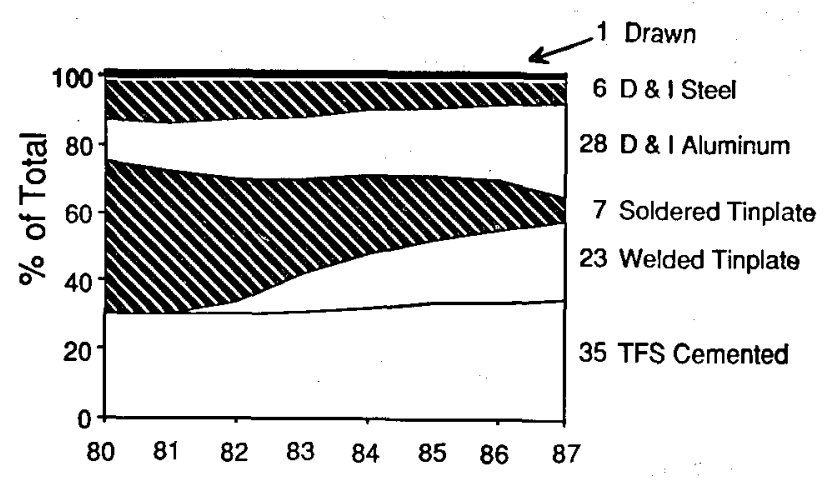

Fiscal Year

Fig. 5. Trends in Japan by type of can.

made from steel in 1987, a decrease from $83 \%$ in 1982 as a result of the more rapid increase in production of aluminum D\&I cans for beverages.

Much effort has been put forth to develop steel easy open ends for beverage cans in Japan, ${ }^{71,73,74)}$ in Europe $^{75)}$ and in Australia ${ }^{76)}$ to provide an all steel can with good performance and openability, and to improve recyclability. In the United States steel FPEO (full panel easy open) ends have enjoyed wide acceptance for pet foods, and at present some companies are equipping to produce a safety style stecl FPEO end for food cans. ${ }^{77)}$ The intent is to provide convenience, but acceptance by the consumer regarding need and cost for ordinary canned fruits and vegetables is yet to be determined.

Paper and plastics have taken over a large share of the food packaging market, mainly for frozen foods or ascptically packaged products which have shorter shelf life than processed foods. The recent development which is most threatening to metal cans is the rigid multilayer barrier plastic containers for processed foods which can be filled and retorted on lines now running cans with only minor changes, and which have a two year shelf life. ${ }^{78)}$ Most involve two outer structural layers of polypropylene (PP) with a middle barrier layer of ethylene vinyl alcohol (EVOH) or polyvinylidene chloride (PVDC). Two adhesive or tie layers are required to bond the outer layers to the barrier material. The most sophisticated of these ${ }^{79)}$ is injection blow molded and employs a desiccant in the tie layers to keep moisture from the EVOH and thus preserve its oxygen barrier capability. Some others are coextruded as multilayer sheet and subsequently thermoformed. Examples of several types are shown in Figs. 6 to 8 . The first of these was designed as a can which could be filled, closed with a metal FPEO, and processed in a rotary continuous cooker. However, the demand at present is for bowl or tray shaped containers which are more esthetic for eating from the package after microwave heating. Microwavability and potential for unique shape are two big advantages of the plastic container. The bowls are being used for salads (pasta, potato, vegetable), stew, chili, lasagna, soups and other single service items. The trays are used for dinner entrees.

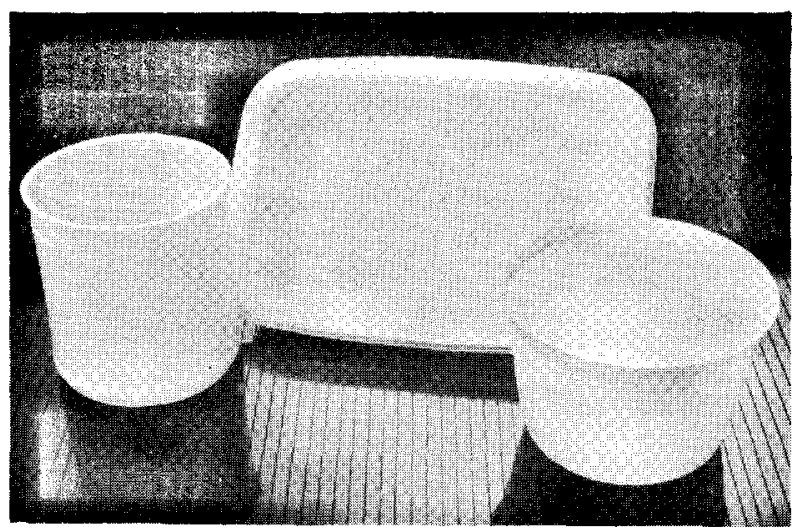

Fig. 6. Multilayer plastic processable containers-can, tray and bowl.

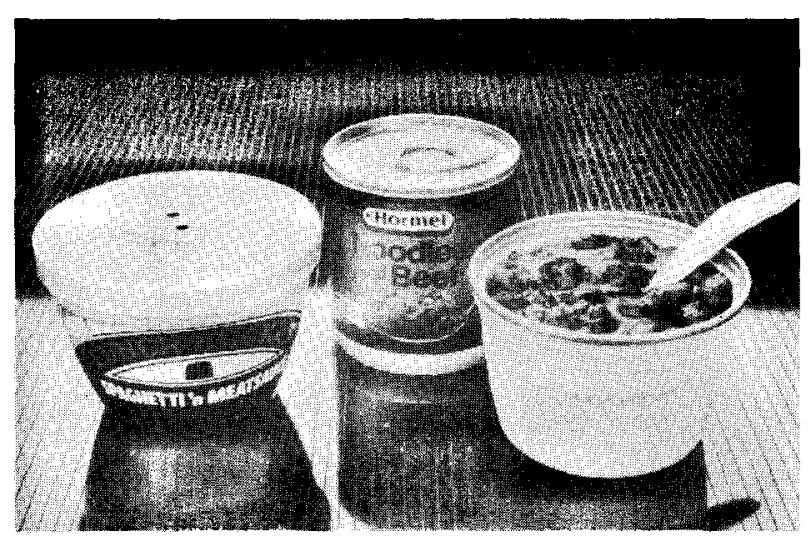

Fig. 7. Processable plastic can and bowls with FPEO tinplate end and plastic overcap for microwaving.

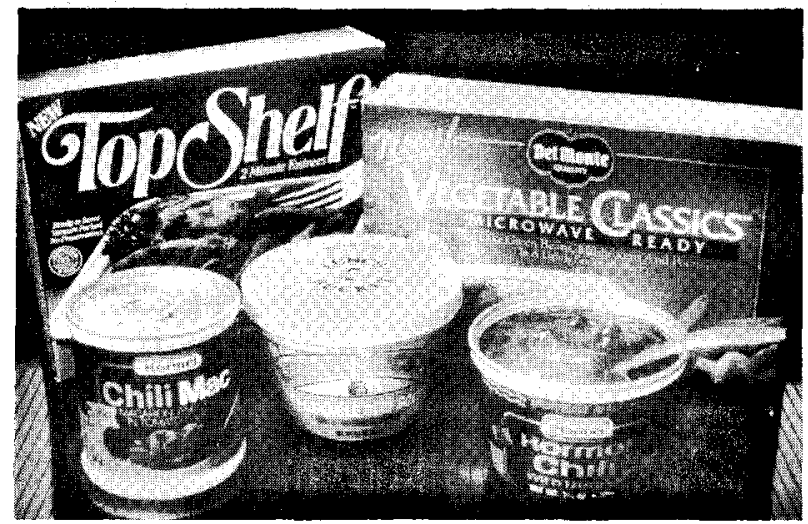

Fig. 8. Processable plastic can, bowls and trays (in cartons).

The solid waste issue in the United States will undoubtedly have profound effects on what happens in the future. Some municipalities, including the village where I live, have instituted separation of garbage to allow recycling of steel, aluminum, glass and paper because of the shortage of available landfills. Plastics have become an issue ${ }^{80}$ because of perceived poor recyclability and lack of degradability as litter and in landfills. Some states and municipalities are proposing laws banning the use of certain plastics and requiring photo- or bio-degradable plastics for packaging, while others place a tax on materials which are not degradable or recyclable. Some plastics pro- 
ducers are developing degradability in certain materials which are most often found in litter. However, much greater emphasis is being placed on recycling. ${ }^{811}$ At least $20 \%$ of the beverage bottles produced from PET (polyethylene terephthalate) are being recycled, much of it into polyester fiber, and a goal of $50 \%$ has been set for 1992. Other facilities are being established to recycle polystyrene foam products and other plastic wastes into useful products other than packaging. However, the concensus regarding solid waste appears to be that a combination of source reduction, separation and recycling, proper incineration, and sanitary landfills will be required to solve the problem effectively.

One last subject that needs mentioning is a new process for improving the overall quality of many canned foods which could win back some of the products now sold frozen or in aseptic packages. The process, invented by McIntyre and Reed, ${ }^{82}$ involves addition of an acidulant, which does not significantly alter flavor, but lowers the $\mathrm{pH}$ of the canned product below 4.6 so that a shorter and lower temperature process can be used. The result is greatly improved texture and color approaching that of freshly prepared foods. ${ }^{83,84)}$ It is believed that this, along with other promotions $\mathrm{s}^{85}$ ) will reverse recent trends and increase the shelf stable processed foods' share of the packaged foods market. The metal can, as well as other processable packages, would benefit.

Thank you very much for the opportunity to address you today. It is a great honor that will be long remembered.

\section{REFERENCES}

1) R. R. Hartwell: Sheet Melal Ind., 15 (1941), 107.

2) R. R. Hartwell: Advances in Food Research, III, Academic Press, New York, (1951), 328.

3) B. S. Clark and K. W. Brighton: Modern Packaging, 19 (1946), 168.

4) R. H. Lueck: Ind. Eng. Chem., Prod. Res. Develop, 13 (1974), No. $1,18$.

5) W. E. Hoare, E. S. Hedges and B.T.K. Barry: The Technology of Tinplate, St. Martins Press, New York, (1965), 311.

6) V.W. Vaurio, B. S. Clark and R. H. Lueck: Analy. Ed.Industr. Engi. Chem., 10 (1938), 368.

7) A. R. Willey, J. L. Krickl and R. R. Hartwell: Corrosion, 12 (1956), No. 9, 433t-440t.

8) E. L. Koehler: Trans. Amer. Soc. Met., 44 (1952), 1076.

9) E. L. Koehler and C. M. Canonico: Corrosion, 13 (1957), No. $4,227 \mathrm{t}-237 \mathrm{t}$.

10) D. W. Bird: Second International Tinplate Conference, ITRI Publ. No. 600, London, (1980), 369.

11) G. G. Kamm, A. R. Willey, R. E. Beese and J. L. Krickl: Corrosion, 17 (1961), No. 2, 84t-92t.

12) G. G. Kamm and A. R. Willey: Corrosion, 17 (1961), No. $2,77 \mathrm{t}-83 \mathrm{t}$.

13) P. R. Carter and T. J. Butler: Corrosion, 17 (1961), No. 2, $72 \mathrm{t}-76 \mathrm{t}$

14) G. J. Ebben and G. J. Lawson: J. Appl. Phys., 34 (1963), 1825.

15) G. G. Kamm and A. R. Willey: Proceedings of the First International Congress on Metallic Corrosion, Butterworths, London, (1961), 493.
16) A. R. Willey: Br. Corrosion J., 7 (1972), 29.

17) G. G. Kamm, A. R. Willcy and R. E. Beese: Mater. Protection, 3 (1964), No. 12, 70.

18) G. G. Kamm and J. L. Krick1: Mechanical Working and Steel Processing IV, Gordon and Breach Sci. Publ., Inc., New York, 44 (1969), 63-101.

19) J. Endle: Br. Corros. J., 7 (1972), 216.

20) R. F. Higgs: U.S. Patent 3,075,897, (Jan. 29, 1963).

21) E. R. Morgan, I. I. Bessen, G. K. Nottman and W. Batz: U.S. Patent $3,285,838$, (Nov. 15, 1966).

22) Tin Int., 60 (1987), No. 7, 150.

23) P. R. Carter: Second Int. Tinplate Conf., ITRI Publ. No. 600, London, (1980), 380.

24) A. N. Laubscher and G. N. Weyandt: J. Food Sci., 35 (1970), 823.

25) T. Janome, T. Hara, I. Matsushima and H. Takano: Tetsu-to-Hagané, 66 (1980), A85.

26) K. Mochizuki, Y. Ban and S. Harada: Tetsu-to-Hagané, 66 (1980), A93.

27) C. H. Peterson: "Shelf Life Evaluation of Selected Steel Chemistries", Proceedings - Shelf Life: A Kcy to Sharpening Your Competitive Edge, Food Processors Inst., Washington, DC, (1981), 41.

28) G. Barbieri, G. Milanese, S. Rosso and T. Corradi: Industria Conserve, 58 (1983), 26.

29) H. B. Chin, J. R. Kimball, B. Allen and J. E. Charbonneau: Third International Tinplate Conference, ITRI Publ. No. 660, London, (1984), 465.

30) G. G. Kamm, S. J. Hotchner, J. L. Krickl and A. A. Kopetz: The Third International Tinplate Conference, (1984), 452.

31) G. G. Kamm, S.J. Hotchner, J. L. Krickl and A. A. Kopetz: Packaging, 57 (1986), April, 32-37.

32) G. G. Kamm, S. J. Hotchner, A. A. Kopetz and R. A. Vitek: Fourth International Tinplate Conference, London, Oct. 1988, ITRI Paper No. 32.

33) Industry Sponsored Program to Investigate Corrosion Anomalies with Tinplate Produced from AK-CG SteelsSummary Report, Can Manufac. Inst., Amer. Iron Steel Inst. and Nat. Food Process. Assoc., Washington, DC, (Jan. 1989).

34) Y. Oyagi, Y. Kitazawa and H. Kanno: Fourth Int. Tinplate Conf., London, Oct. 1988, ITRI Paper No. 29.

35) Y. Oyagi, Y. Tsukamoto, T. Asai and T. Hayashi: Tetsuto-Hagané, 73 (1987), A-127.

36) P.J. Aubrun, M. P. Henrion, G. A. Pennera and F. J. Tissier: Fourth Int. Tinplate Conf., London, Oct. 1988, ITRI Paper No. 30.

37) G. A. Pennera, P. J. Aubrun and P. M. Marsal: "Effect of Syrup Sugars on the Behavior of Plain Tinplate Cans Filled with Light Colored Fruits", 2nd World Congress of Food Technology, Barcelona, March 1987, Comite Asesor Int. Ciensia y Technologia.

38) C. D. Kim and E. J. Helwig: Fourth Int. Tinplate Conf., London, Oct. 1988, ITR I Paper No. 31.

39) M. Tsurumaru, Y. Suzuki and K. Masuda: Fourth Int. Tinplate Conf., London, Oct. 1988, ITRI Paper No. 28.

40) D. R. Kidder, G. G. Kamm and A. A. Kopetz: Proceedings of the American Society of Brewing Chemists, Assoc. Services, Inc., St. Paul, MN, (1967), 138.

41) H. Uchida and O. Yanabu: U.S. Pat. 3,113,845, (Dec. 10, 1963).

42) Y. Kitamura: U.S. Pat. 2,998,361, (Aug. 29, 1961).

43) S. Yonezaki, H. Nitto and H. Asano: U.S. Pat. 3,296,100, (Jan. 3, 1967).

44) G. G. Kamm, A. R. Willey and N. J. Linde: J. Electrochem. Soc., 116 (1969), 1303.

45) S. Yonezaki: Sheet Metal Ind., 48 (1971), No. 1, 25. 
46) N. Azzeri and G. Baudo: Br. Corros. J., 10 (1975), 28.

47) T. Inui, H. Kuroda, K. Hizuka, F. Kunishige and Y. Kondo: U.S. Pat. 4,455,355, (June 19, 1984).

48) S. Maeda, T. Asai, H. Omata and H. Asano: Japanese Pat. 1,350,481, (Jan. 4, 1978).

49) W. T, Chiappe: Modern Packaging, 43 (1970), No. 3, 82.

50) H. Kuroda, I. Onoda, T. Inui and Y. Kondo: Second Int. Tinplate Conf., London, ITRI Publ. No. 600, (1980), 124.

51) R. Allouf and C. Mergy: Second Int. Tinplate Conf., ITRI Publ. No. 600, London, (1980), 241.

52) J. Lempereur and L. Renard: Third Int. Tinplate Conf,, ITRI Publ. No. 660, London, (1984), 185.

53) R. Allouf: Third Int. 'Tinplate Conf., ITRI Publ. No. 660, London, (1984), 247.

54) M. L. Black and E. J. Helwig: Third Int. Tinplate Conf., ITRI Publ. No. 660, London, (1984), 170.

55) H. Takano, H. Kagechida, Y. Yomura and T. Hara: Third Int. Tinplate Conf., ITRI Publ. No. 660, London, (1984), 201.

56) H. Moriyama, N. Shimizu, Fujimoto, Nomura and Onoda: Third Int. Tinplate Conf., ITRI Publ. No. 660, London, (1984), 214.

57) K. Mochizuki, H. Nakajouji, Ogata, Ichida and Irie: Third Int. Tinplate Conf., ITRI Publ. No. 660, London, (1984), 227.

58) S. Miyazaki, Yoshizawa and Makino: Fourth Int. Tinplate Conf., London, Oct. 1988, ITRI Paper No. 11.

59) R. W. Kaecher, K. E. Carlson and G. A. Clark: "Corrosion/Performance Aspects of Two-Piece Containers", Proc. Eighth Int. Congress on Canned Foods, Thessalonika, Int. Comm. Canned Foods, (1983), 11-24.

60) F. L. Ghurch: Modern Metals, 42 (1986), April, 28.

61) A. J. Klein and E. W. Hitchler: "Formability of Double Reduced Steel for Deep Drawn Food Containers", North Amer. Tinplate Conf., Chicago, 1985, AISI \& ITRI.

62) M. Sodeik, K. Täffner and F. Weber: Trans. Iron Steel Inst. Jpn., 28 (1988), 672.

63) J. Endle: U.S. Patent 3,620,934, (Nov. 16, 1971).

64) N. Ooniwa, Y. Yomura and T. Adaniya: Fourth Int. Tinplate Conf., London, Oct. 1988, ITRI Paper No. 10.

65) Y. Takesue, O. Yoshioka, H. Kawamura and T. Fujimoto:
Tetsu-to-Hagané, 73 (1987), A-139.

66) Can Manufacturers Institute Report-Metal Can Shipments Report December, 1987, Ernst and Whinney, Washington, DC, (April 1988).

67) S. J. Hotchner and G. G. Kamm: Food Tech., 21 (1967), No. 6, 95.

68) "Can Manufacturers Institute Report-Metal Can Shipments Report, September 1988", Ernst and Whinney, Washington, DC, (Jan. 1989).

69) R. Heuer: Packaging, 32 (1987), June, 80.

70) E.J. Clowes: U.S. Pat. 4,522,049, (June 11, 1985).

71) T. Hada: "Can Market and Technical Trends in Canmaking in Japan", NMDA Annual Meeting, Baltimore, Oct. 1988, NMDA.

72) Packaging Japan, 6 (1988), No. 47, 35.

73) H. Asano and N. Arai: Third Int. Tinplate Conf., ITRI Publ. No. 660, London, (1984), 281.

74) K. Shimizu, J. Tanabe, S. Acki and Y. Kondo: Fourth Int. Tinplate Conf., London, Oct. 1988, ITRI Paper No. 33.

75) R. Sauer: Fourth Int. Tinplate Conf., London, Oct. 1988, ITRI Paper No. 34.

76) K. Jessop and D. Salm: Fourth Int. Tinplate Conf., London, Oct. 1988, ITRI Paper No. 35.

77) F. L. Church: Modern Metals, 43 (1988), No. 12, 98.

78) M. Schlack: Plastics World, 44 (1986), Feb. 32.

79) J. A. Wachtel, B. G. Tsai and C. J. Farrell: Plastics Eng., 41 (1985), Feb. 41

80) D. Snow: Waste Age, 19 (1988), No. 7, 131.

81) "Plastics and Recycling: Debunking a Myth", New York Times, (Feb. 23, 1989), 23.

82) D.J. McIntyre and D. E. Reed: U.S. Pat. 4,741,911, (May 3, 1988); 4,789,553, (Dec. 6, 1988).

83) R. P. O'Neill: Assoc. of Food Indust., (1987), 60.

84) D. D. Duxbury: Food Processing, 49 (1988), May, 75.

85) M. Levine: Supermarket Business, 43 (1988), No. 9, 132.

(Based on the Yukawa Memorial Lecture delivered by Mr. G. G. Kamm at the 117th ISIJ Meeting, April 5, 1989, at Yokohama National University in Yokohama) 